\title{
EFFECTS OF RESERPINE AND ADRENALINE ON THE SINOATRIAL NOTCHED POTENTIAL IN RABBIT
}

\author{
NOBORU TODA \\ Department of Pharmacology, Faculty of Medicine, Kyoto University, Kyoto \\ Received for publication October 26, 1961
}

In the coursc of studies in this laboratory on the mode of action of catecholamines on the transmembrane potential of the cxtirpated atrium of rabbit (1), some of the potentials recorded from the pacemaker area (West) responded differently to reserpinc and adrenaline from the typical pacemaker potentials. The potential under this study was recorded from the area which was somewhat wider than the triangular pacemaker area shown schematically by West (2). This potential was characteristic in a notching of the upstroke and a slow rate of depolarization, and was very sensitive to reserpine and adrenaline. The notched potential in the sinoatrial node of rabbit's heart was at first reported by West (2), who studied the distribution of the potential. Although the similar notched potentials have been reported in the atrioventricular node of mammalian heart $(3,4)$, the smooth muscle of uterus (5) and the sinoauricular funnel of amphibian heart (6), the exact nature of the potentials remains to be settled. In the present report the responses of the notched potential recorded from the sinoatrial node of rabbit's heart were studicd. It is cxpected that the responses of the potential to reserpine and adrenaline might have some contribution to elucidate the mechanism of the pacemaker activity.

\section{METHODS}

Albino rabbits, weighing 1.8 to $2.2 \mathrm{~kg}$, were killed through haemorrhage by cutting of both common carotid arteries. The heart was cxtirpated and the right auricle was separated from the heart. Immediately thereafter, the auricle was fixed on the cork plate immersed in warm $\left(30^{\circ} \mathrm{C}\right)$ and $\mathrm{O}_{2}$-saturated modified Tyrode solution. The volume of the solution in the bath was $50 \mathrm{ml}$. The composition of the modified Tyrode solution is as follows: $\mathrm{NaCl} 8.6 \mathrm{~g}, \mathrm{KCl} 0.2 \mathrm{~g}, \mathrm{CaCl}_{2} 0.2 \mathrm{~g}, \mathrm{MgCl}_{2} 0.05 \mathrm{~g}, \mathrm{NaH}_{2} \mathrm{PO}_{4} 0.2 \mathrm{~g}, \mathrm{Na}_{2} \mathrm{HPO}_{4}$ $1.6 \mathrm{~g}$ and glucose $1.0 \mathrm{~g}$ in $1000 \mathrm{ml}$. The preparation always showed a rhythmical automatic contraction for 8 to 14 hours.

A glass capillary tube filled with 3 molar $\mathrm{KCl}$ solution was used as a different electrode. As an indifferent electrode a platinum wire immersed in the nutrient solution of the bath was used. The potential changes of the single muscle fiber were recorded following the method of Matsumura and Takaori (7). The potential changes amplified through d.c. amplifier were photographed from a cathode-ray oscilloscope by use of a continuous recording camera. When it was required, the potentials were recorded by use of an inkwriting oscillograph. 
All the drugs employed were administered into a side chamber connected with a main preparation chamber of the bath. The concentration of the drug in the bath was expressed as $\mathrm{g} / \mathrm{ml}$. Two and half milligram of reserpine dissolved in $1.0 \mathrm{ml}$ of a mixture of propylene glycol $(50 \mathrm{mg})$, phosphoric acid $(2.0 \mathrm{mg})$, glucose $(25 \mathrm{mg})$ and distilled water was used as a stock solution. $\mathrm{pH}$ of the rescrpine solution was 2 to 3 . None of the potential recorded was affected by the administration of the solvent less than $0.2 \mathrm{ml}$. As adrenaline hydrochloride only $l$-form was used.

\section{RESULTS}

\section{1) The sinoalrial notched polential}

An atypical transmembrane potential which was different from that of pacemaker was recorded several millimeters apart from the area where the pacemaker potential was recorded. The potential obtained from the vicinity of the pacemaker area was distinguished from the pacemaker and atrial non-pacemaker potentials in the points that the former potential showed a notching followed by a slow rate of depolarization. Moreover, the potential frequently showed a prepotential succeeded by a notching and by a rising phase of the action potential (Fig. 1B). The farther was the distance of the recording clectrode from the pacemaker area, the less was the slope of the prepotential. Some of the notched potential obtained from the area several millimeters far from the pacemaker area showed the notched potential without an appearance of the prepotential, as shown in Fig. 1C. The height and duration of the notching, usually 5.8 to $20 \mathrm{mV}$ and 14.5 to $34.9 \mathrm{msec}$, were subjected to a considerable variation. Consequently, this potential seemed to coincide

A

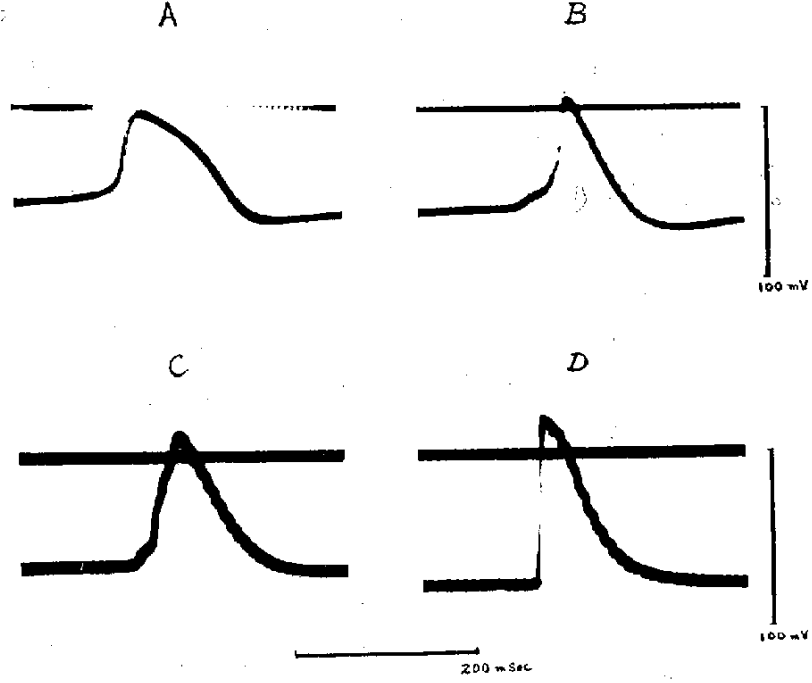

FIG. 1. Typical patterns of the pacemaker potential (A), the notched potential with a prepotential and a large notching (B), the notched potential with a small notching $(\mathrm{C})$ and the atrial nonpacemaker potential (D). 
TARILE 1. The magnitude of the action potential (ap), the diastolic potential (dp), the overshoot (os) and the total duration of the action potential (td) in the pacemaker*, the notched and the atrial non-pacemaker* potentials.

* Marshall, 1957(8)

\begin{tabular}{|c|c|c|c|c|c|c|}
\hline & \multirow{2}{*}{$\stackrel{a p}{(m V)}$} & \multirow{2}{*}{$\underset{(\mathrm{mV})}{\mathrm{dp}}$} & \multirow{2}{*}{$\stackrel{\mathrm{os}}{(\mathrm{mV})}$} & \multirow{2}{*}{$\begin{array}{c}\mathrm{td} \\
(\mathrm{msec})\end{array}$} & \multicolumn{2}{|c|}{ Notching } \\
\hline & & & & & $\begin{array}{l}\text { Height } \\
\text { (msec) }\end{array}$ & $\begin{array}{c}\text { Duration } \\
(\mathrm{mV})\end{array}$ \\
\hline Paccmaker potential* & $66 \pm 1.0$ & $61 \quad 10.67$ & $5+0.45$ & $189 \pm 8.1$ & & \\
\hline Non-paccmaker potential* & $89-0.89$ & $73 \pm 0.70$ & $16 \div 0.45$ & $135+4.9$ & & \\
\hline Notched potential ( $N: 20)$ & $86 \pm 1.8$ & $76 \pm 2.0$ & $10 \perp 0,59$ & $150 \pm 3.0$ & $6-20$ & $15-55$ \\
\hline
\end{tabular}

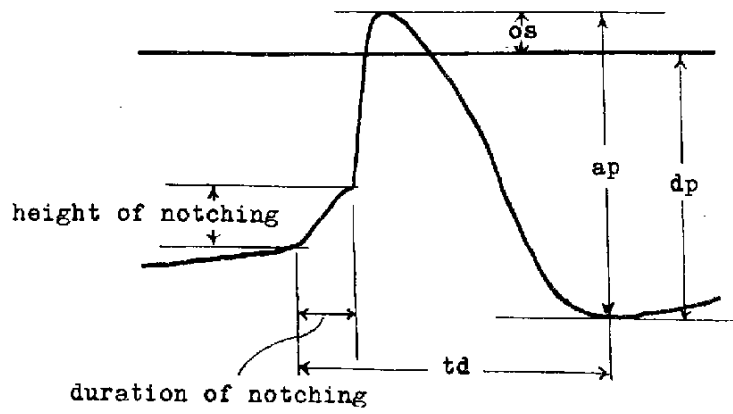

with the description of the notched potential by West (2). Fig. IB and $1 \mathrm{C}$ show typical pattern of the notched potentials with and without prepotential. In Table 1 the height and duration of the action potential, the magnitude of the diastolic potential and the overshoct in the record of the notched potential are compared with those of the pacemaker and atrial non-pacemaker potentials. The figure and table show the similarities of the notched and pacemaker potentials in the total duration of the action potential and in the depolarization velocity, but show considcrablc dissimilarities in the height of action potential and in the overshoot.

Fig. 2 is the schematic representation of the sinoatrial node of rabbit shown from the endocardial surface. From $B$ area the typical pacemaker potential was usually obtained. The notched area where West has obtained the notched potential is the triangular part encircled with the dotted lines in Fig. 2. In this experiment the notched potential was also obtained from $\mathrm{A}$ and $\mathrm{C}$ areas. The demarcation of the notched area from the pacemaker arca was usually not clcarcut and the dimension of the notched area was subjected to a considerable variation. The pacemaker area was incompletely surrounded by the notched area. The notched potential was never

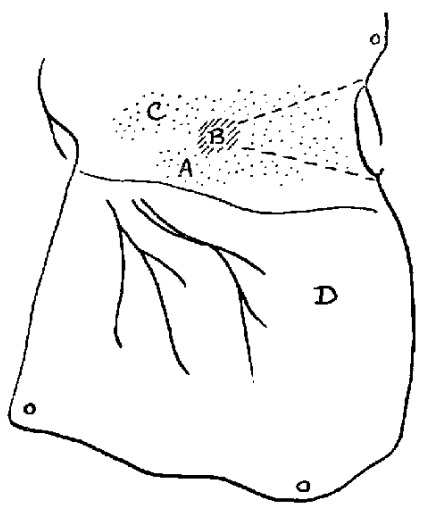

FIG, 2. Schematic representation of the area where the pacemaker, notched and non-pacemaker potentials were recorded (see text). 
obtained from D area in Fig. 2, where the atrial non-pacemaker potential was recorded. This area was easily differentiated from the pacemaker and notched arca macroscopically. The transmembrane potcntial which lacked the prepotential and notching but difiered from the atrial non-pacemaker potential in the total duration was sometimes obtained from the vicinity of the sinoatrial node. However, this potential responded to reserpine in a manner similar to the pacemaker or atrial non-pacemaker potential.

\section{2) Effects of reserpine on the pacemaker potential and on the notched potential}

The administration of $10^{-6}$ to $10^{-5}$ of reserpine in the bath gave rise to the following characteristic effects on the pacemaker and notched potentials. Marked effects of reserpine were observed especially on the notched potential. The ratc of rhythm gradually decreased in all the pacemaker potential, the notchcd potential and the atrial non-pacemaker potential. The effects of reserpine on the pacemaker potential were almost the same as those reported previously (I). As shown in Fig. $3 \Lambda$ and $3 B$, depression of the action potential, decrease of the slope of prepotential, increase of the total duration of the potential, minute diminution of the maximal diastolic potential, retardation of the depolarization velocity and unchanged threshold potential were the main effects. Increase of the total duration, depression of the magnitude of action potential and unchanged resting potential by the same concentration of reserpine were observed in the atrial non-

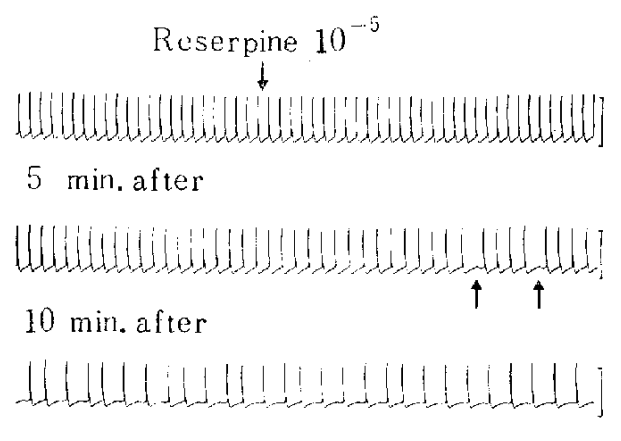

20 min. after

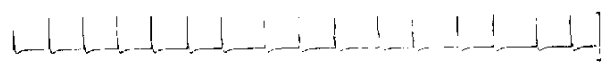

30 min, after

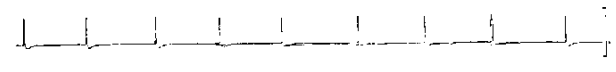

$40 \mathrm{~min}$. after

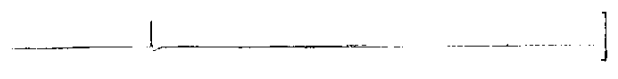

FIG. 3A. Effcets of $10^{-5}$ of reserpine on the pacemaker potential. The arrows indicate the abortive depolarization (see text). The scale of vertical lines at right side of each tracing is 100 $\mathrm{mV}$. Time scale $: 1 \mathrm{sec}$. Scales are same in the following figures.
I

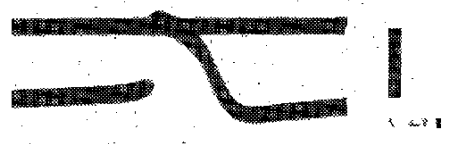

II

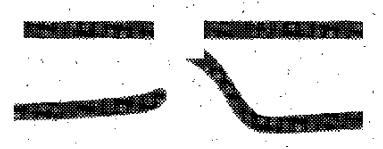

III
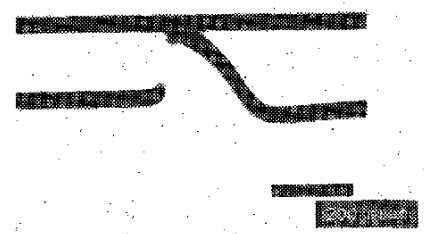

Fig. 3B. Effects of $10^{-5}$ of reserpine on the pacemaker potential. I : before, II $: 15$ minutes after, III: 25 minutes after. 
pacemaker potential.

The notched potential also responded to reserpine in a manner similar to the pacemaker potential during an early stadium (for about 20 minutes). But the characteristic effects of rescrpine on the notched potential appeared earlier than those on the pacemaker potential. Twenty to fourty minutes after $10^{-5}$ of reserpine the spike potential was suddenly abolished from the notched arca. Thereafter, only a minute trace of the electrical pattern was recorded. Fig. $4 \mathrm{~A}$ and $4 \mathrm{~B}$ show the results. This electrical pattern could be interpreted as the depressed notching which did not fire to the usual spike potential and was called notch-potential in this report. The typical notch-potentials are shown in Fig. 4B, 5B, 7G and 9. In some of the preparations the notch-potential and the notched

A

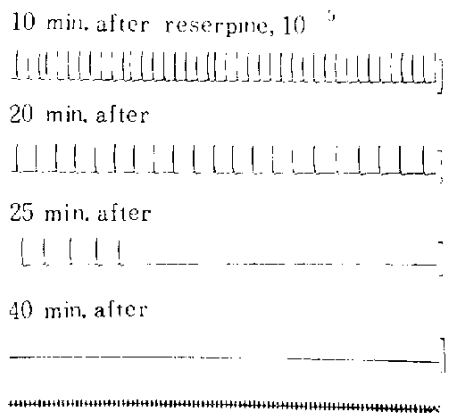

B

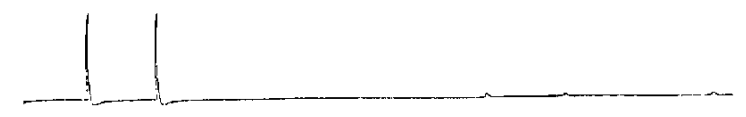

FIG. 4. Effccts of $10^{-i}$ of reserpine on the notched potential. $(B)$ is an enlarged figure of effects of reserpine at 25 minutes and 40 minutes after the administration. The abrupt disappearance of the spike potential and the appearance of the notch-potential were observed.

A

Reserpine $10^{-5}{ }^{-5} 5^{-}$

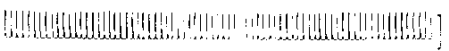

$5 \mathrm{~min}$ after

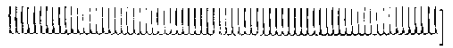

$10 \mathrm{~min}$, after

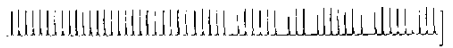

15 min. aftcr

L. L....ed.

30 min. after

50 milit. after

65 mis alter

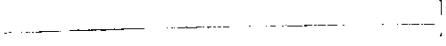

B
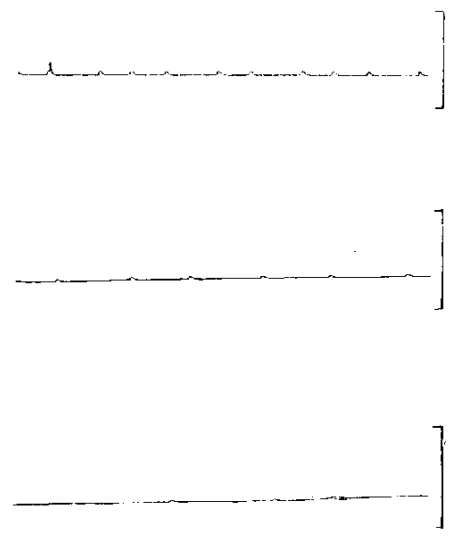

FIG. 5. Effects of $10^{-5}$ of reserpine on the notched potential. (B) is an enlargement from right half of the lower part of (A). A gradual diminution in the height of the notch-potential at 30,50 and 85 minutes after the administration of reserpine. 


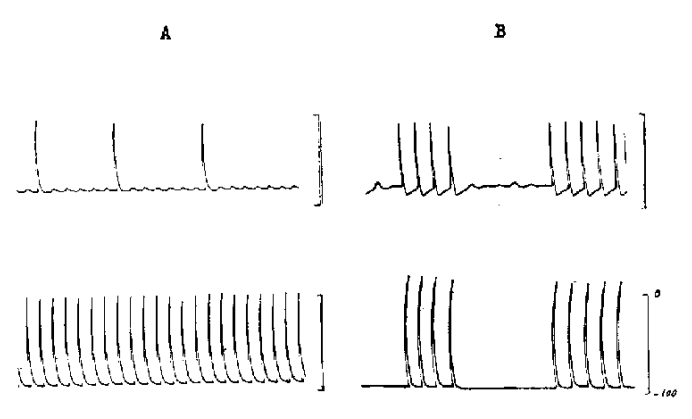

\section{HH+H+H+H\#+1+H}

FIG. 6. Comparison of the effects of $10^{-5}$ of reserpine on the pacemaker potential and the notched potential in reference to the non-pacemaker potential. (A) The notched potential and the notch-potential recorded from notched area in the course of reserpine action are shown in the upper tracing. Lowcr tracing shows the non-pacemaker potential recorded at the same time. (B) The pacemaker potential and the abortive depolarization (see text) are shown in the upper tracing. Lower tracing shows the non-pacemaker potential. potential with depressed spike irregularly appeared beforc the full development of the notch-potential, as shown in Fig. 5A and 5B. When the notch-potential had appeared, both pacemaker and atrial non-pacemaker potentials were little affected irrespective of decrease of the frequency. The results are shown in Fig. 6. In the course of time after the administration of reserpine the magnitude and frequency of the notch-potential gradually decreased and at last the notch-potential disappeared in accordance with the disappearance of the pacemaker and atrial non-pacemaker potentials. In few of the preparations which had not shown any sign of the notching before, the marked notching in the upstroke of the potential appeared in the course of reserpine action. On the contrary to the abovementioned case, some of the notching decreased in height after reserpine.

TABLE 2, The measured values of each component of the notched potential affected by reserpine in Fig. 7. ap : the magnitude of the action potential. mdp : maximal diastolic potential. tp : threshold potential. os : overshoot. td : total duration of the action potential (tp-1 and tp-2: see text).

\begin{tabular}{|c|c|c|c|c|c|c|c|c|}
\hline \multirow{2}{*}{\multicolumn{2}{|c|}{$\underset{(\mathrm{mV})}{\mathrm{ap}}$}} & \multirow{2}{*}{$\underset{(m V)}{m d p}$} & \multirow{2}{*}{$\begin{array}{c}\mathrm{tp}^{\mathrm{p}}-1 \\
(\mathrm{mV})\end{array}$} & \multirow{2}{*}{$(\mathrm{tp}-2$} & \multirow{2}{*}{$\begin{array}{c}\mathrm{os} \\
(\mathrm{mV})\end{array}$} & \multirow{2}{*}{$\underset{(\mathrm{msec})}{\mathrm{td}}$} & \multicolumn{2}{|c|}{ Notching } \\
\hline & & & & & & & $\begin{array}{l}\text { Height } \\
(\mathrm{mV})\end{array}$ & $\begin{array}{c}\text { Duration } \\
(\mathrm{msec})\end{array}$ \\
\hline A & 85.0 & 75.9 & 64.7 & 55.5 & 9.1 & 148.9 & 8.9 & 55.0 \\
\hline B & 78.0 & .74 .9 & 64.7 & 52.4 & 3.1 & 161.8 & 7.3 & 62.6 \\
\hline C & 75.1 & 72.0 & 61.6 & 43.1 & 3.1 & 189.3 & 6.1 & 72.5 \\
\hline D & 65.7 & 73.4 & 64.2 & 43.1 & - & 208.4 & 6.1 & 84.0 \\
\hline $\mathrm{E}$ & 27.5 & 68.8 & 64.2 & 43.1 & - & 213.9 & 5.5 & 87.7 \\
\hline $\mathrm{F}$ & - & 64.2 & 64.2 & - & - & -- & 4.6 & 120.7 \\
\hline G & - & 64.2 & 64.2 & - & - & - & 4.6 & 120.7 \\
\hline
\end{tabular}

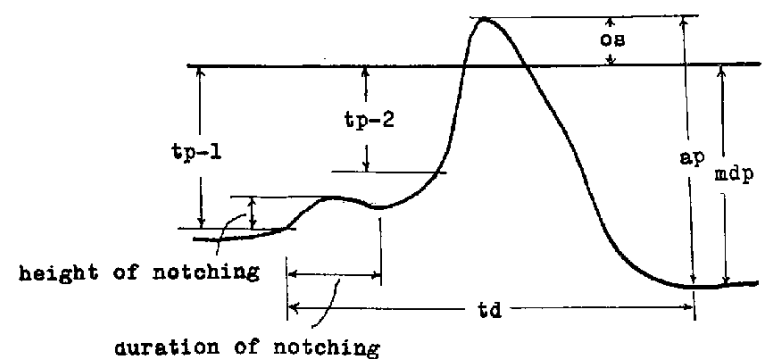


The slope of prepotential of the notched potential decreased gradually before the manifestation of the nolch-potential. After the manifestation of the notch-potential, the slope of prepotential disappeared, and the maximal diastolic potential decreased to the same level of the thrcshold potential. The threshold level of the notched potential with prepotential or the resting level of the notched potential without prepotential remained unchanged.

Fig. 7 shows the effects of $10^{-5}$ of reserpine on the notched potential at $10,20,30$, 40,45 and 50 minutes after the administration, respectively (B-G). Tablc 2 and Fig. 7

A

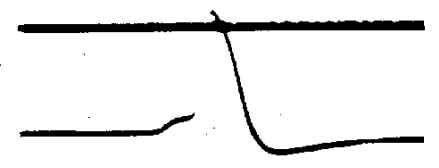

B

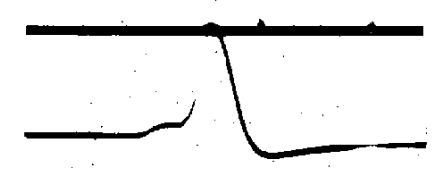

c

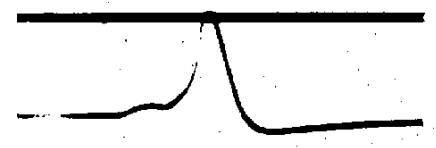

$\dot{L}$

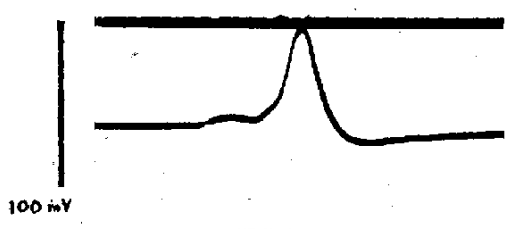

200 msec
$E$
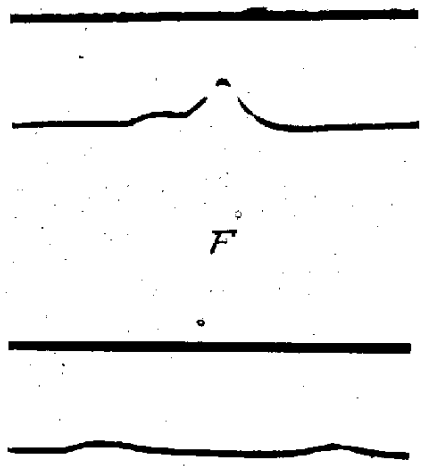

G

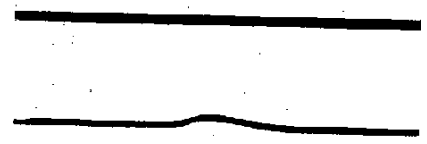

H

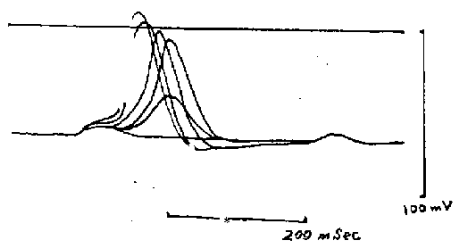

FIG. 7. Photographic representations of the changes of the notched potential in response to $10^{-5}$ of rescrpine at $10,20,30,40,45$ and 50 minutes after the administration respectivcly. (A) Before reserpine, (B-G) After reserpine, (H) Superimposed figure of potential changes. 
show the changes of the magnitude of the action potential, the maximal diastolic potential, the overshoot, the total duration of action potential, and the duration and height of notching after the administration of $10^{-5}$ of reserpine. In the course of time after reserpine the duration of the potential from the rising phase to the end of the repolarization was prolonged. The magnitude of the action potential was gradually depressed and the action potential finally disappeared. But there remained the notch-potential. In Fig. 7 the action potential shows the spike potential with preceding prepotential and the notching before the administration of reserpine (A). Ten minutes after the administration of $10^{-5}$ of reserpine the action potential was depressed in magnitude (Fig. 7B). In the course of reserpine action, the action potential was further depressed in magnitude and there appeared another small notching immediately after the prolonged first notching (Fig. 7C). Further effects of rescrpine were the flattening and the increase of the duration of the first notching and the further depression of the spike potential (Fig. 7D and 7E). At last, the duration of the depolarization phase was approximately equal to that of the repolarization phase. In Fig. $7 \mathrm{~F}$ the spike potential completely disappeared and the notchpotentials werc distinctly separated. The superimposed figure of the potential changes in the course of reserpine action is shown in Fig. 7H. If the notching of the notched potential is regarded as a constituent of the depolarization phase, the value of tp-l in the figure of Table 2 shows the threshold of the notched potential. This value was hardly affected by reserpine. On the other hand, if the notching represents a local response to cvoke the firing of the spike, the value of tp-2 in Table 2 shows the threshold, which was gradually decrcased in the course of reserpine action. The marked effects of reserpine on the notched potential were at first the depression of the spike potential and the increase of the duration of the depolarization phase, and then the abolishment of the spike.

In the pacemaker potential the abortive small pattern of wave which did not fire to a usual spike potential was sometimes observed, when the rate of rhythm decreased after reserpine. This small pattern of wave is called an abortive depolarization in this report. The arrows in Fig. 3A show the typical abortive depolarization at 6 minutes after the administration of $10^{-5}$ of reserpine. The interval between the foregoing spike and the abortive depolarization was longer than that between the abortive depolarization and the succeeding spike. The abortive depolarization usually did not return to the original level of the maximal diastolic potential, so that the next prepotential started from the elevated level to fire the succeeding spike potential. In some cases of the abortive depolarization the next prepotential started without the manifestation of any repolarization sign. In the course of reserpine action the height of the abortive depolarization was markedly depressed and this depolarization finally disappeared.

Thus, there were two ways of the decrease of frequency in the pacemaker potential after reserpine. The first was that some of the usual spike potentials turned to the abortive depolarization which gradually increased in number. The other way was that the interval between each spike potential became longer, so that the decrease of the 
frequency resulted. Usually the decrease of the frequency appeared in a mixed way of these two.

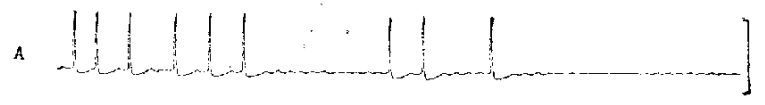

In some of the preparations there appeared many abortive depolarizations beforc the complete abolishment of the pacemaker potential, as shown in Fig. 8A. Whenever the pacemaker spike had disappeared and the abortive depolarizations of the pacemaker

B

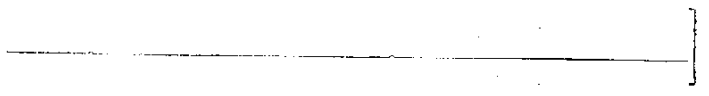

$H+H+H+H+H+t+1+1+H+t+t+H+1+t$

FIG. 8. Comparison of the mode of disappearance of the pacemaker potential $(A)$ with that of the notch-potential (B) in response to reserpine.

had appeared, the usual spike pattern of the non-pacemaker did not appear. The result is shown in Fig. 6B. On the other hand, the abrupt disappearance of the depressed pacemaker potential is illustrated without the manifestation of further fluctuating abortive depolarization in Fig. 3.

As mentioned above, when a considerable decrease of the frequency of the potential and an appearance of the abortive depolarization after reserpine were observed, the pacemaker spike was not much affected, and the atrial non-pacemaker potential was not evoked by the abortive depolarization of the pacemaker but was evoked by the pacemaker spike potential. On the other hand, when the notched potential changed to the not.chpotential in response to reserpine, the frequency of the atrial non-pacemaker spike potential was the same as that of the notch-potential (Fig. 6A). Even in the case in which the notch-potential appeared by reserpine, the pacemaker and the atrial non-pacemaker potentials remained normal. This may give some clues on the mode of the notched potential.

3) Antagonistic effect of adrenaline on reserpine action

The notch-potential induced by the administration of $10^{-5}$ of reserpine was recovered to the original notched potential in response to adrenaline. The concentration of adrenaline to antagonize the reserpine action differed considerably in each preparation, but was usually in the range of conccntration of $10^{-7}$ to $10^{-5}$. At first the magnitude of the notch-potential gradually increased and one to two minutes after the administration of adrenaline there started the spike potentials at the peak of the notch-potential followed by the increase of the frequency. Several minutes were required to restore the normal notched potential. In this casc some of the notchings seemed to be masked by the
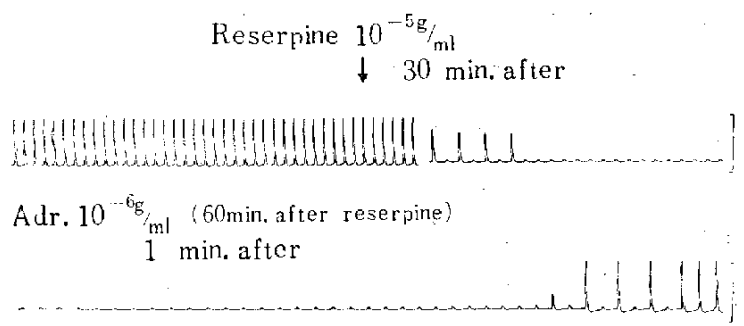

3 min. after

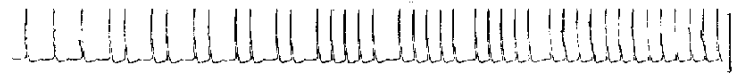

FIG. 9. Effects of $10^{-5}$ of adrenaline on the notch-potential induced by the administration of $10^{-5}$ of reserpine. 
increased spike potential. Fig. 9 shows the antagonistic effects of $10^{-6}$ of adrenaline on the notch-potential caused by the administration of $10^{-5}$ of reserpine. As seen in the figure, though the threshold potential of prepotential remained unchanged, the increase of the slope of prepotential and the slight increase of the maximal diastolic potential were observed. Thesc effects of adrenaline were oppositc to the effects of reserpine.

The similar antagonistic effects of adrenaline were also observed on the depressed pacemaker potential induced by the administration of reserpine. One to three minutes after adrenaline the abortive depolarization suddenly appeared between the spikes and then some of the abortive depolarizations fired to the spikes, resulting in the increase of the frequency. At last the complete restoration of the spike potential and the increase

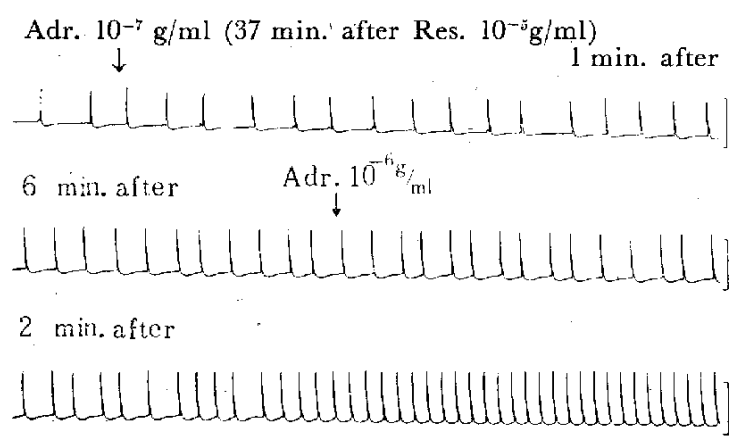

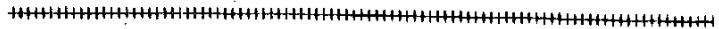

Fic. 10. Effects of $10^{-7}$ and $10^{-6}$ of adrenaline on the pacemaker potential affected by reserpine. of the frequency were obtaincd. The result is shown in Fig. 10. The concentration of adrenaline to antagonize the reserpine action on pacemaker potential did not show any marked difference from that of the aminc on the notchpotential induced by the same procedure, and was also subjected to a considcrable individual variation.

4) The irreversibility of the reserpine action by the replacement of the modified. Tyrode solution

When the full depression of the notched or pacemaker potential by reserpine had developed, the repeated replaccment of the nutrient solution in which the preparation was immersed did not restore the normal pattern and the normal rhythm of the potentials. Sometimes the depression of the spike became more marked by this procedure. In these cases adrcnaline also antagonized the reserpine effects. The antagonistic effects and concentration of adrenaline on either notched potential or pacemaker potential were almost the same irrespective of the presence of reserpine in the nutrient solution.

\section{DISCUSSION}

Some of the transmembrane potentials which wcre recorded from the vicinity of the sinoatrial node of rabbit's heart by use of the microelectrode technique differed from the pacemaker and the atrial non-pacemaker potentials. The characteristic figures of the potential consisted in the notching between the diastolic potential and the upstroke of the spike potential, and in the long duration of the depolarization phase. This potential coincided with the notched potential described by West, bcing taken from the triangular part of the sinoatrial node of rabbit. The similar notched potential recorded from the 
atrioventricular node was suggested by Sono et al. (4) to play some important role in the conduction of impulse through the node. Hoffman et al. $(3,9)$ reported that the administration of acetylcholine to the atrioventricular node of the extirpated rabbit's heart revealed the notched potential followed by the retarded and markedly depressed depolarization. They discussed the possibility that the development of the notched potential resulted from the decremental conduction of impulse through the specialized structure of the atrioventricular node. They further suggestcd that the notched potential in the atrioventricular node might have some relation to the histological convergence of small muscle fibers to a large fiber. This convergence of the muscle fibers might cause a conduction dclay and a decremental conduction of impulse.

In the present studies the response of the notched potential to reserpine and adrenaline was compared with those of the pacemaker and the atrial non-pacemaker potentials. The notched potential was much sensitive to reserpine. Although some decrease of the frequency of the potential occurred for all the potentials about 20 to 40 minutes after the administration of $10^{-5}$ of reserpine, the notched potential was depressed more markedly than the other potentials, and at last the spike of the notched potential disappeared before the development of the marked depression of the other potentials. There remained a small wave which was called as notch-potential. This notch-potential was very similar in shape to the slow potential described by Goto et al. $(5,10)$ in the uteri of rat and mouse. Using microelectrode technique they recorded the notched potential in response to electrical stimuli of a certain range of intensity. The duration and height of the notching also varied with the intensity of the stimuli. In response to subthreshold stimuli the uterus showed only the notching which did not fire to the spike. They discussed the possibility of the notching to result from the local electrotonic change of the muscle fiber from the adjacent stimulated fibers. The time course of the notch-potential in the present experiment was very close to that of the slow potential recorded by Goto et al.

Marshall (8) also recorded a small potential, like the so-called notch-potential in this paper, from the sinoauricular preparation of rabbit's heart which was cooled about $11^{\circ} \mathrm{C}$ in vitro. Besides, the pacemaker potential of the cooled preparations was some what depressed, while the atrial non-pacemaker potential did not fire to a usual spike potential. She suggested that the dissociation of both potentials in response to the cooling resulted from the decrease of the diastolic potential of the pacemaker and the non-pacemaker, and interpreted that the administration of acctylcholine elicited propagated action potential in the non-pacemaker because of an increase in the diastolic membrane potential toward the normal level. In the present cxperiment, however, neither the decrease of diastolic potential in the non-pacemaker nor the conduction blockade from pacemaker to atrial non-pacemaker was observed throughout the reserpine action. The maximal diastolic level of pacemaker potential was slightly decreased without any change in the threshold potential after reserpine.

The notched potential usually had a prepotential and a notching followed by the spike potential. There are two possibilitics to clucidate the mechanism of the prepoten- 
tial in the notched potential. The first is an electrotonic response of the muscle fiber propagated from the pacemaker fiber which has an automatic rhythm. But this may be less possible because of a slow onset and long duration of the prepotential. Another possibility is that the muscle fiber from which the potential was recorded might have an automaticity independent on the pacemaker activity. But there is no evidence to support this mechanism.

Three possibilities on the genesis of the notching may be suggested. The first possibility is that an electrotonic response might be conducted to the muscle fiber in the notched area through a narrow bridge which lies between muscle fibers of the sinoatrial node and is enough small in safety factor for the conduction of impulse. There is also another mechanism which interferes the conduction of impulse. Hoffman et al. (3) also suggested that the intercalated discs which transversely cross the muscle fiber of the heart might interfere the conduction. The second possibility is the suggestion of the existence of different pathways for the conduction of impulse from the paccmaker to the muscle fiber in the notched arca. As shown in Fig. 7D and 7E, the fact that the notched potential was separated into two components, a notch-potential and a notched potential, in response to reserpine may result from the delayed arrival of the impulses from the pacemaker and consequently from time difference of arrival to the muscle fiber via a collateral pathway. In other words, the effect of rcserpine on the notched potential is interpreted that the full spike was not fired in response to the first stimulus, and that the other delayed impulse from the pacemaker arrived at the muscle fiber and elicited firing. The third possibility is that the notching might be a junction potential transmitted across the muscle junction which was suggested to be a discontinuous space between muscle fibers (Goto et al.) within the sinoatrial node. However, there may be no evidence to doubt the syncytial structure of the heart muscle.

In the course of reserpine action the notch-potential was markedly depressed. The administration of adrenaline increased the height of the depressed notch-potential. When the height of the notch-potential reached a critical level, the notching fired to a usual notched potential. Accordingly, the height of notching seemed to be a determining factor for the firing of the notched potential. As seen in Table 2, the level of flexion from prepotential to notching was frequently stable at a definite period of reserpinc action, while the level of flexion from notching to the upstroke of the spike gradually rose during the same period. If the latter level of flexion is a determining factor for firing of the notched potential, it gradually rises in the course of reserpine action. At thc same time, the level of threshold in the pacemaker remained unchanged during the reserpine action.

In some of the records from pacemaker area the abortive depolarization appeared in the course of reserpine action before the abolishment of the pacemaker potential. The similar pattern has already been shown by West et al. (11). They reported that when adrenaline was administered to the preparation, the abortive diastolic prepotential appeared between the normal pacemaker potentials and reached threshold to fire. Such 
firing of the abortive diastolic prepotential by adrenaline resulted in the increase of rate of the potential. The similar result was obtained in the present experiment. The height and frequency of the abortive depolarization in the preparation trcated by reserpine gradually increased after the administration of adrenaline and at last rcached threshold and fired. The antagonistic effect of adrcnaline on the notch-potential was almost the same as that of adrenaline on the abortive depolarization.

The effects of reserpine on the pacemaker potential of the extirpated rabbit's heart were studied in the previous report (1). The administration of $10^{-5}$ of reserpinc depressed the spike potential and the frequency of the pacemaker, and at last abolished them. The similar effects of reserpine on the notched potential of the same preparation were also obtained in this experiment, though the effects of reserpine appeared much faster on the notched potential. These results seemed to have some relation with the depletion of catecholamines from the heart by reserpine. The depletion of catecholamincs from the heart by reserpine was already shown by many authors. The catecholamines of the rabbit's heart consist in largely noradrenaline [98\% by Muscholl (12), 97\% by Paasonen et al. (13)]. Matsuo in this laboratory studied the effects of reserpine on the noradrenaline content of rabbit's heart in vitro and in vivo (personal communication). When 1.0 $\mathrm{mg} / \mathrm{kg}$ of reserpine was injected intravenously 16 to 20 hours before the experiment, the decrease of noradrenaline was more than $90 \%$. The extirpated hcart of this animal pretreated with reserpine showed almost normal configuration of the potential, though the potential showed a decreased rhythm. On the other hand, 2 or 3 hours after the administration of $10^{-5}$ of reserpine all the pacemaker, the notched and the non-pacemaker potentials of the extirpated heart were abolished and then the decrease of noradrcnaline was only 30 to $40 \%$. The discrepancy of the depletion of noradrenaline by reserpine in vitro and in vivo, and the discrepancy of the response of the potential to deplction of noradrenaline from the heart muscle by reserpine need some interpretation. Schümann et al. (14) already postulated that the denervation of adrenal gland in rabbit decreased the amount of depletion of catecholamines by reserpine. As was shown in the previous experiment, the restarting concentration of adrenaline on the stillstanding potential which had lost its normal rhythm by reserpine did not differ markedly irrespective of the washing-out of reserpine from the preparation. Moreover, Tachi and Matsuo (personal communication) showed that the content of noradrcnaline of the restarted heart by adrenaline was almost the same as that of the stillstanding heart by. reserpine, the amines of both preparations being reduced by about $30 \%$ of the normal content. Their results show that the minute amount of amines which was not detected by the chemical assay of catccholamincs employed, restarted the stillstanding heart by reserpine. It is assumed that though the heart of the animal which was injected with $1.0 \mathrm{mg} / \mathrm{kg}$ of reserpine intravenously, was depleted about $90 \%$ of the content of noradrenaline, the potential pattern of the heart was maintained by the minute amount of the endogenously liberated amines. On the contrary, the extirpated heart which was treated by reserpine and was deprived of $30 \%$ of noradrenalinc could not liberate enough endogenous catecholamine to maintain 
its normal pattern of the potential.

Bülbring and Burn (15) suggested that the endogenously liberated acetylcholine from the heart muscle fiber initiated and maintained the rhythmic contraction of the heart. The results in the present experiment also show that the minute amount of catecholamines endogenously liberated from the sinoatrial node plays the similar role in initiation and maintenance of the pacemaker and the notched potentials. The responses of the notched potential to reserpine and adrenaline may give some contribution to elucidate the mechanism of the pacemaker activity.

\section{SUMMARY}

By use of microelectrode technique the notched potential is recorded from the vicinity of the pacemaker area of the extirpated rabbit's heart. The notched potential is characteristic in a notching before the manifestation of the upstroke of the action potential, and in a slow risc of the depolarization. This potential also responds somewhat differently to reserpine and adrenaline from the pacemaker and the atrial non-pacemaker potentials.

Before the manifestation of the marked depression of the paccmaker and the atrial non-pacemaker potentials by a dose of $10^{-5}$ of reserpine, the notched potential changes to the notch-potential, which is a small electrical pattern (about 6 to $20 \mathrm{mV}$ in height) without a spike. Furthermore, the notch-potential gradually decreases in height and at last disappears with the abolishment of the pacemaker potential.

In response to adrenaline the notch-potential increases in height. When the magnitude of the potential becomes high cnough to fire, the spike potential follows. On the other hand, the depressed pacemaker potential by reserpine increases in height and frequency after the administration of adrenaline until the full pacemaker potential appcars. The abortive depolarization, which sometimes appears between the depressed pacemaker spikes in the course of reserpine action, is a small pattern of electrical wave. Further, the abortive depolarization caused by reserpine fires to the normal spike in response to a definite concentration of adrenaline.

Acknowledgment. The author wishes to thank Professor K. Shimamoto, Doctor M. Fujiwara and Doctor Sh. Takaori of this Department and Professor T. Otani of the Department of Physiology of Kyoto University for their helpful advice and criticism.

\section{REFFRFNCES}

1) Tona, N. : TiIs Journal 10, 78 (1960)

2) WList, T.G. : J. Pharmacol. 115, 283 (1955)

3) Holmman, B.F., De Carvat.ho, A.P., Mello, W.G. and Cranefield, P.F. : Circul. Res. 7, 11 (1959)

4) Sano, T., TASAki, M. and Shimamoto, T. : Ibid. 7, 700 (1959)

5) Goto, M., Kurryama, H. And Abe, Y.: Proceedings of the Japan Academy 36, 509 (1960)

6) Iwamoio, M. : J. Physiol. Soc. Japan 20, 701 (1958) (Japanese text)

7) Matsumura, M. and Takaori, Sh. : This Journat. 8, 143 (1959) 
8) Marshall, J.M. : Circul. Res. 5, 664 (1957)

9) Cranefield, P.F. and Hohman, B.F. : Ibid. 7, 19 (1959)

10) Klriyama, H.A., Goto, M., Maeno, T., Abe, Y. and Ozaki, S. : Electrical Activity of Single Cells. p. 243 Igakushoin, Tokyo (1960)

11) West, T.C., FalK, G. and Cervoni, P. :J. Pharmacol. 117, 245 (1956)

12) Muscholl, E. : Arch. exp. Path. Pharmak. 237, 350 (1959)

13) PaAsonen, M.K. And KRAYer, O. : J. Pharmacol. 123, 153 (1958)

14) Kroneberg, G. and Schümann, H.J.: Arch. exp. Path. Pharmak. 23I, 349 (1957)

15) Bülbring, E. And Burn, H. :J. Physiol. 108, 508 (1949) 